\title{
Prevalence and associated factors to rotavirus infection in children less than 5 years in Enugu State, Nigeria
}

\author{
C. D. Ojobor ${ }^{1,2}$ C. V. Olovo ${ }^{1}$ L. O. Onah ${ }^{1,3} \cdot$ A. C. Ike $^{1} \mathbb{C}$
}

Received: 19 February 2020/ Accepted: 20 July 2020/Published online: 6 August 2020

(C) Indian Virological Society 2020

\begin{abstract}
Rotavirus is an important cause of morbidity and mortality in children 5 years and below. An epidemiological study was carried out to determine the prevalence of rotavirus in Enugu state and factors that contribute to the incidence in the state. Stool samples were collected from 179 children from different parts of the state. Rotavirus antigen was detected using enzyme immunoassay kit. A standardized structured questionnaire was used to obtain additional information from the parents/guardian of the children. Chi square was used to analyze the results and significance was determined at 0.05 . The results showed $31.5 \%$ prevalence of rotavirus among children with acute gastroenteritis (AGE) and $25.7 \%$ prevalence in the general population. The prevalence was highest (60.9\%) among children 0-12 months and decreased as the age increased. Rotavirus infection was significantly higher in bottle-fed children than in those feed exclusively breast milk. More viruses were detected in $\mathrm{O}(48.8 \%)$ and A (47.6\%) blood group children than in children of other blood groups. More rotavirus caused AGE occurred in dry season compared to wet season, with highest incidence of both AGE and rotavirus infection occurring in January. Rotavirus diarrhoea was significantly associated with fever, vomiting and dehydration. The results of this study show that rotavirus continues to be an important cause of diarrhoea in children in this part of Nigeria and emphasize the need to factor in
\end{abstract}

A. C. Ike

anthonyc.ike@unn.edu.ng

1 Department of Microbiology, Faculty of Biological Sciences, University of Nigeria, Nsukka, Enugu State, Nigeria

2 Department of Molecular Genetics, Faculty of Medicine, University of Toronto, Toronto, Canada

3 Lona Biomedical Laboratories, Obollo, Enugu State, Nigeria rotavirus and other viral agents in the diagnosis and treatment of diarrhoea in children 5 years and below.

Keywords Children · Diarrhoea $\cdot$ Enzyme immunoassay (EIA) $\cdot$ Prevalence $\cdot$ Rotavirus

\section{Introduction}

Diarrheal diseases have been implicated to be major causes of morbidity and mortality with significance in developing countries where it accounts for 15-30\% of death in children less than the age of 5 years [17]. Rotavirus (RV) gastroenteritis was recorded to be responsible for about 215,000 deaths among children below the age of 5 years in 2013. It was also estimated that approximately half (49\%), of these RV deaths occurred in four developing countries of which Nigeria was one [33]. A high prevalence of 56\% for RV disease has been found to occur in Nigeria making the country an important zone for the disease [30]. More so, an estimated mortality of 31,000 deaths due to RV disease was recorded for the country in 2013 (World Health Organization Bulletin, 2016 http://www.who.int/ vaccine_safety/committee/reports/wer8907.pdf?ua=1). Due to the high death rates in children, vaccination to prevent severe disease outcomes after RV infection is an essential public health strategy.

Rotaviruses are members of the Reoviridae family containing a double stranded RNA and are classified into 7 groups $(A-G)$ on the basis of distinct antigenic and genetic properties [7]. The outer capsid consists of the two major neutralizing antigens; a glycoprotein, termed the G-type (VP7) and a protease-sensitive protein, P-type (VP4) [3]. These antigens are responsible for conferring immunity and hence are targets for vaccine development. About 35 
G-genotypes and 50 P-genotypes have been described in humans and animals globally and of these, $12 \mathrm{G}$ types and $15 \mathrm{P}$ types have been identified in humans [28]. However, serotypes G1P [23], G2P [7], G3P [23], G4P [23] and G9P [23] are thought to be important causes of diarrhoea in infants and young children worldwide [13]. Rotaviruses are stable in the environment and are present in estuary samples. They can survive for long periods of time on toys and ordinary surfaces found in most homes and are relatively resistant to most soap and disinfectants, thus preventing a child from exposure can be difficult.

This study reports the prevalence of RV infection in children under the age of 5 in Enugu and Nsukka metropolises, South Eastern Nigeria between 2014 and 2015. It also associates the occurrence of the disease to blood group, antibiotics usage, gender, and age of the infants, as well as the weather seasons that occur in the country.

\section{Materials and methods}

\section{Sample collection}

A total of 179 stool samples were collected from children seeking medical attention in clinics/hospitals. Questionnaires were administered and completed accordingly by the parents/guardians of subjects. The stool samples were collected using sterile wide mouth universal containers, covered and labelled accordingly.

\section{Inclusion and exclusion criteria}

The inclusion criteria include: age $0-5$ years of both sexes, diarrhoeic and given consent. Children who had been on antimicrobial agents were not excluded in the study. The exclusion criteria include: age above 5 years of both sexes, no consent given. A diarrheic case in this study is defined as any child between the ages of zero and five passing loose, liquid, watery, non-bloody stool, three to five times within a 24-h period (Acute gastroenteritis; AGE). Cases also include subjects who are vomiting and show manifestations of dehydration. The controls were both children (in the same age bracket as the cases) presented with an illness other than diarrhoea and with no history of it on the day of, or in the week preceding sampling, and healthy children with no symptoms of the infection.

\section{Study area/population}

Some hospitals/clinics in Nsukka and one hospital in Enugu zones were selected for the study and sampling was carried out from September 2014 to May 2015. Diarrhoeic stool samples were taken from children aged 0-5 seeking medical care in clinics/hospitals, with symptoms of acute gastroenteritis. The labelled stool samples were transported on ice to the laboratory, Department of Microbiology, University of Nigeria, Nsukka, where they were stored at $4{ }^{\circ} \mathrm{C}$ and assayed within $24 \mathrm{~h}$ upon arrival.

\section{Viral detection}

Each $10 \%$ faecal suspension was screened for the presence of rotavirus using commercially prepared enzyme immunoassay (EIA) kit (RIDASCREEN ${ }^{\circledR}$ Rotavirus (RBiopharm AG, Darmstadt, Germany)). All assays were performed according to the manufacturer's instruction.

\section{Statistical analysis}

Chi square was used to analyze the data and $p$ values less than 0.05 was considered statistically significant.

\section{Results and discussion}

\section{Prevalence of rotavirus disease in children in this study}

Viral diarrhoea has led to a significant number of hospitalizations and mortality of children in sub-Saharan Africa and rotavirus is the leading cause of viral acute gastroenteritis (AGE) in children between the age of 0 and 5 years. Given that acute infantile diarrhoea is caused by other biological agents such as bacteria and parasites, it becomes very necessary that proper and robust diagnosis is carried out to limit incidences of mistreatment, which is a healthcare problem in many African societies. This study looked at the prevalence of rotavirus in Enugu state, Nigeria and examined some factors that may have contributed to the prevalence.

The overall prevalence of rotavirus in children below 5 years in the study area shows that of the 179 children subjects that were sampled, 146 of them showed symptomatic manifestations of acute gastroenteritis (AGE), 33 of them (controls) had no AGE. Out of the 146 AGE subjects, $46(31.51 \%)$ tested positive to rotavirus infection. None of the $33(0 \%)$ without AGE tested positive to RV infection. In total, the percentage prevalence of rotavirus infection was $25.70 \%$.

The prevalence of the disease in this study is similar to the results of previous works in Lagos state, South Western Nigeria [2, 4, 23] and in Enugu State, South Eastern Nigeria [31] who reported 22.3\%, 37.5\%, $45.3 \%$ and $46 \%$ prevalence respectively. It is also similar to other studies conducted in Africa, including 22.73\% prevalence reported in Burkina Faso [10], and 29\%, 29\% and 30\% prevalence 
for Zimbabwe, Tanzania and Ethiopia respectively [20]. Other studies in Nigeria have reported lower prevalence including $11.9 \%$ in Maiduguri [1], $16.3 \%$ in Kebbi, $14.8 \%$ in Sokoto, and $15.5 \%$ in Zamfara state [28]. A study conducted in Ilorin, Nigeria did show much higher (55.9\%) prevalence of the disease in the sampled children [22].

The varying percentage prevalence seen above may be influenced by disparity in climate, environment, socioeconomic factors, cultural practices, method of diagnoses, and period and length of sampling. For instance, the high prevalence obtained in the study in Ilorin [22] may have been due to the methodology employed in their viral detection. While most of the other studies, including ours, used ELISA or Enzyme Immunosorbent Assays (EIA) specific for Group A rotavirus, they further employed electropherotyping assays which identify rotavirus belonging to other groups.

\section{Prevalence of rotavirus disease in children with respect to Location}

Prevalence of rotavirus infection according to different locations shows that of the 146 children subjects with AGE that were sampled, $29(55.77 \%)$ of the 52 samples obtained from Lona Biomedical Centre, Obollo tested positive to RV infection. Additionally, 7 (29.17\%) of the 24 samples collected from Chidubem Specialist and Children Hospital, Nsukka were positive for rotavirus infection; $2(15.38 \%)$ of 13 samples from Ochile Medical Laboratory, Nsukka, 2 (14.86\%) of 14 samples from Nsukka Health Centre and 6 (13.95\%) of 43 samples from Mother of Christ Specialist Hospital, Enugu, all tested positive to RV disease.

The differences in prevalence according to location can be attributed to population density, social status of families and levels of personal and environmental hygiene. From our data, we observe that $80 \%$ of these children patients, who tested positive to the virus, lived within the same vicinity that were densely populated, were from low-income families, and lacked appropriate means of faecal disposal. These factors may have contributed to increased ease of spread of the virus among these children. Interestingly, the role of overcrowding in propagating rotavirus spread has been previously reported [19]. On the contrary, the least prevalence $(13.95 \%)$ obtained in this study was from Mother of Christ Specialist Hospital, Enugu, which is mostly patronised by children from middle-class homes, who lived in environments with better sanitation practices and much less crowding.
Prevalence of rotavirus disease in sampled children with respect to age

The relative prevalence of RV infection in different age groups of children subjects with AGE is indicated in Fig. 1. Results showed that $60.87 \%$ prevalence of RV infection existed in children between the ages of 0-12 months, $19.57 \%$ in children $13-24$ months, $8.69 \%$ in children 25-36 months and those 37-48 months, and $2.19 \%$ in children 49-60 months.

The finding that rotavirus prevalence decreased with increase in age is supported by results from several other studies [7, 8, 14, 21, 31]. The reason for increased susceptibility of the $0-12$ months age group to the disease is assumed to be due to the high exposure of children in this group to contaminated materials. Children in this group are known to put everything into their mouths, and given that the virus survives on surfaces and fomite including toys, for long period of time, it is not far-fetched to assume that they potentially could be infected quite easily.

The decrease in prevalence of $\mathrm{RV}$ infections after 24 months might imply that by age 2 , most children would have been infected in their lifetime and are protected against subsequent symptomatic re-infection. Natural immunity has also been suggested as a reason for decreased incidence with age [24]. However, RV-antigens have been detected in older children in some studies [12, 18, 34].

\section{Prevalence of rotavirus disease in children with respect to gender}

More number of samples of children with AGE were obtained from females (86) in comparison to their male counterparts (60). For the male children, 22 (36.67\%) samples tested positive to rotavirus disease while 24 $(27.91 \%)$ samples of the female children tested positive. Both male and female control groups, 13 and 20 samples respectively tested negative to $\mathrm{RV}$ infection (results not shown).

There was no significant difference in the burden of rotavirus disease between male and female children but the preponderance of the disease was more in males. This is similar to the findings from previous studies. Higher but insignificant rotavirus in males than females has been reported [3], while others have reported significantly higher infections in males than females [21,31]. The reasons for the difference in detection rate between males and females are however, not known. 
Fig. 1 Prevalence of rotavirus infection in different age groups of children with acute gastroenteritis

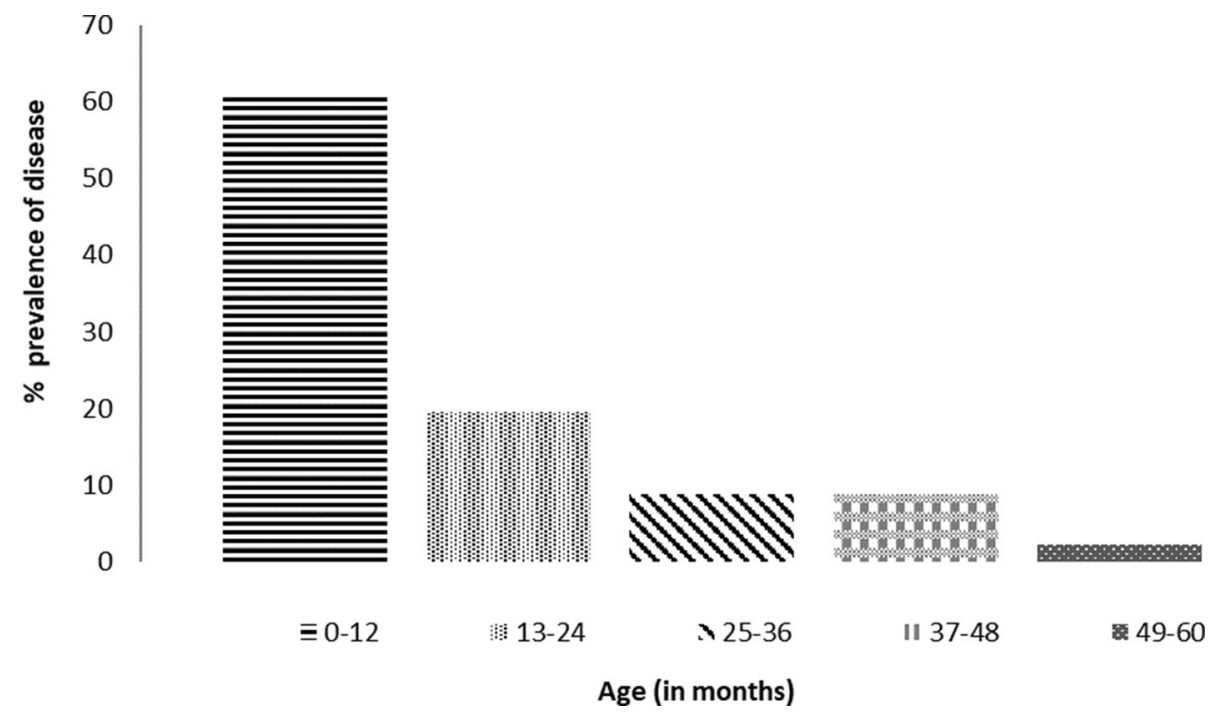

\section{Effects of feeding method on rotavirus disease burden in children}

To compare breast-fed children with bottle-fed children, information was sought on feeding method used. Only 66 respondents gave information on breast-feeding of their wards. Out of 48 breastfed children tested, 10 (20.83\%) were positive to RV infection while out of 18 bottle-fed children tested, $9(50 \%)$ were positive to rotavirus. There was a statistical difference between children feed by the two methods $(p=0.01)$.

The result showing that children who were breast-fed significantly had less of the disease than their counterparts that were exclusively bottle-fed is corroborated by the result of Das et al. [9] who found that there was significant reduction in rotavirus-antigenemia in the breast-fed group compared to non-breastfed infants, especially in 0-6 month age group. Antigenemia is a common phenomenon detected in RV-infected children and is characterized by transient presence of antigen in the blood. It has also been reported that children being breastfed in the period of disease inception, reduced the risk of AGE due to RV [26]. The reduction in the incidence of RV-disease seen in the breast-fed group may be due to the protective effect of the $\operatorname{IgA}$ which is quite abundant in breast milk. Study has established that $\operatorname{Ig} \mathrm{A}$ was important for clearance and critical for protection from rotavirus infection in mice [5]. However, a study carried out from February to April 2008 in Uganda reported that breastfeeding was not protective to rotavirus disease [35]. The result of our study with regards to the type of feeding should be interpreted with caution because of the relatively low number of children who were exclusively bottle-fed, a practice which is not common in Nigeria.

\section{Effects of $\mathrm{ABO}$ blood grouping on rotavirus disease burden in children}

Prevalence of RV infection with respect to the ABO blood group systems of the children is as shown on Table 1. The blood grouping of 82 AGE children subjects was obtained in total and the results show that $10(47.62 \%)$ of 21 blood group A subjects were positive to rotavirus infection. Also, $2(20 \%)$ of 10 group B subjects, $1(12.50 \%)$ of 8 group AB children and $21(48.84 \%)$ of 43 group $O$ children all tested positive to rotavirus.

Similar findings were reported in a study carried out in Egypt, where children with blood group A (43\%), followed by $\mathrm{O}(26 \%)$, were reported to have the highest prevalence of RV disease [11]. This was attributed to host susceptibility of specific human RV strains and the pathogenesis being influenced by the genetically controlled expression of the different human blood group antigens (HBGAs). It is established that HBGAs are recognised as susceptibility and cell attachment factors for gastric pathogens like rotavirus [6, 32], norovirus [16, 32] and Helicobacter pylori [16]. Moreover, some researchers found that cells engineered to express the A antigens on their surface were easily infected by the RV strains. They also reported that

Table 1 Effect of the ABO blood grouping on rotavirus disease burden in children

\begin{tabular}{lccl}
\hline Blood group & Total no. sampled & No of positives & \%Prevalence \\
\hline A & 21 & 10 & 47.62 \\
B & 10 & 2 & 20.00 \\
AB & 8 & 1 & 12.50 \\
O & 43 & 21 & 48.84 \\
Total & 82 & 34 & \\
\hline
\end{tabular}


blocking the A antigen prevented RV infection in human intestine [16]. On the contrary, another study had found no correlation between the risk of RV-gastroenteritis and any blood group type [15].

\section{Effects of seasonality on rotavirus disease burden in children}

Figure 2 illustrates the prevalence of rotavirus-caused AGE between September 2014 and May 2015, in relation to seasonality. The incidence of AGE was at its peak in the month of January 2015. Out of 64 subjects who had AGE in January, $35(54.7 \%)$ were caused by rotavirus. In December, $9(37.5 \%)$ of 24 children with acute gastroenteritis, had their illness linked to rotavirus disease. The least cases were in April, May and November 2014 where no child sampled tested positive to the disease. There was a significant difference of the disease prevalence in drier months (November-March 2015) compared to wet months (Sept-Oct 2014 and April-May 2015) (Table 2).

Other studies have shown that rotavirus infection slightly peaked in the drier months of December-April [25, 29, 31]. In the larger African geographical context, the seasonality of RV infections varied across Africa, reflecting the difference in the climatic conditions [20]. Most studies have associated RV disease to common symptoms such as dehydration, fever and vomiting.

\section{Comparative analyses of epidemiological and physical features of rotavirus disease}

Table 2 reports the comparative analyses of the epidemiological and physical features of children with rotavirus disease and their control group. Symptoms such as fever, vomiting and dehydration have $p$ values that associate them significantly to rotavirus disease. The disease is also shown to have strong association with drier seasons comparatively to wet seasons.

In this study, $65 \%$ of children infected with the disease showed symptoms of fever, 56\% were vomiting and 39\% of the children were dehydrated. All of these symptoms showed strong statistical significance when compared to the control groups of those showing same symptoms, had gastroenteritis but not of RV origin. A study in Zaria, Nigeria found that $78.4 \%$ of children studied were dehydrated due to RV infectivity [25]. Other studies have also supported through evidence that rotavirus diarrhoea is dehydrating diarrhoea $[18,27]$.

In conclusion, this study demonstrates the significance of RV in localities such as Nsukka and Enugu metropolises. It has also revealed that a good number of cases of acute gastroenteritis are of viral origin. This is important as most diarrhoeic illnesses are usually treated as bacterial or parasitic infections, as similar symptoms are manifested. It also highlights the importance of sanitation and hygiene in the communities. Studies such as this provide data that can enable healthcare practitioners to form a more robust diagnostic programme which will take into account the possibilities for viral diseases. Furthermore, further
Fig. 2 Seasonality of acute gastroenteritis and the rotavirus infections among 146 children suffering from AGE between September 2014 and May 2015
Number of acute gastroenteritis

日Number of rotavirus-caused acute gastroenteritis

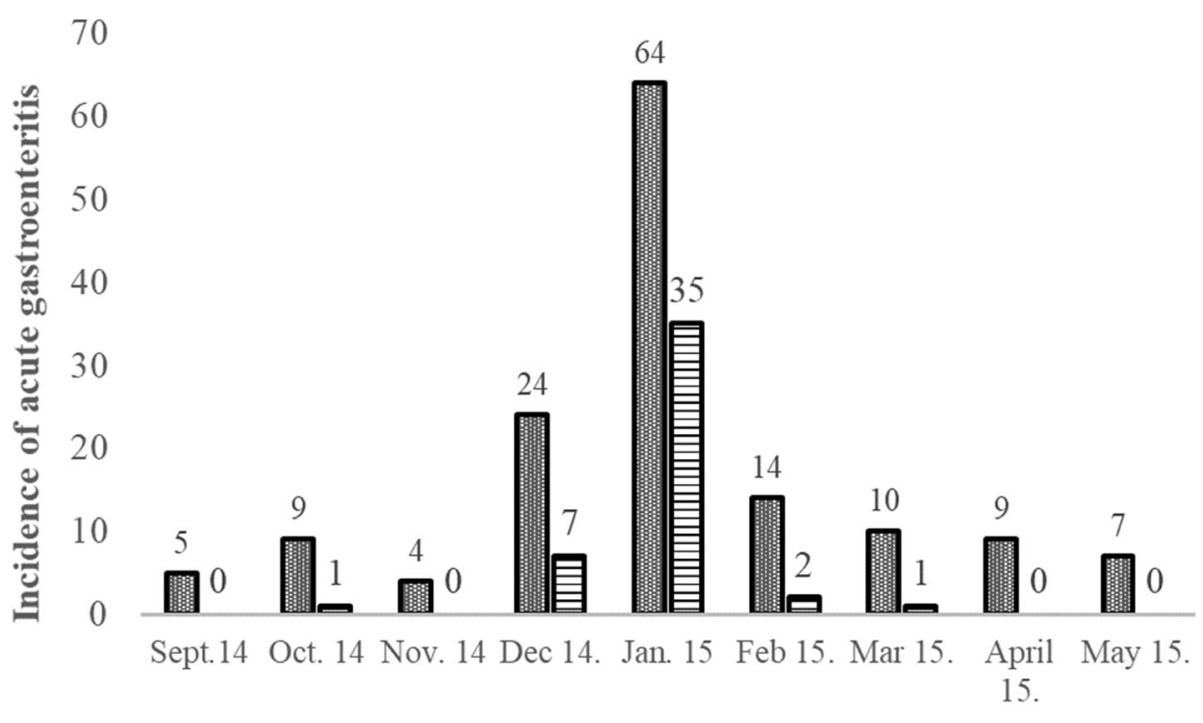

Month (Year) 
Table 2 Comparative analyses of the clinical and epidemiological features of children subjects with or without rotavirus disease

\begin{tabular}{|c|c|c|c|}
\hline Epidemiological and physical characteristics & Rotavirus diarrhoea $(\mathrm{N}=46)$ & Non-rotavirus diarrhoea $(\mathrm{N}=100)$ & $p$ value \\
\hline \multicolumn{4}{|l|}{ Season } \\
\hline Wet (Sept/Oct 2014-April/May 2015) & $1(2.17 \%)$ & $30(30 \%)$ & $0.00001(\mathrm{~S})$ \\
\hline Dry (Nov 2014-March 2015) & $45(97.83 \%)$ & $70(70 \%)$ & \\
\hline \multicolumn{4}{|l|}{ Symptoms } \\
\hline Fever & $30(65.22 \%)$ & $38(38 \%)$ & $0.01(\mathrm{~S})$ \\
\hline Vomiting & $26(56.52 \%)$ & $36(36 \%)$ & $0.05(\mathrm{~S})$ \\
\hline Dehydration & $18(39.13 \%)$ & $21(21 \%)$ & $0.05(\mathrm{~S})$ \\
\hline
\end{tabular}

research that will explore the prevailing serotypes of $\mathrm{RV}$ in South-eastern Nigeria is also necessary for the future purpose of vaccine development.

Funding No financial or non-financial benefits have been received or will be received from any party related directly or indirectly to the subject of this article.

\section{Compliance with ethical standards}

Conflict of interest Authors declare no conflicting interests.

Ethical approval Ethical approval for this study was obtained from the Ethical Committee of the Faculty of Biological Sciences, University of Nigeria, Nsukka.

\section{References}

1. Adah MI, Rohwedder A, Olaleye OD, Durojaiye OA, Werchau H. Serotype of Nigerian rotavirus strains. Trop Med Internat Health. 1997;2:363-70.

2. Alabi SA, Audu RA, Oyedeji KS, Mafe AG, Uhunangho JE. Viral, bacterial and parasitic agents associated with infantile diarrhoea in Lagos, Nigeria. Nig J Med Res. 1998;2:7-10.

3. Aminu M, Esona MD, Geyer A, Steele AD. Epidemiology of rotavirus and astrovirus infections in children in northwestern Nigeria. Ann Afr Med. 2008;7(4):168-74.

4. Audu R, Omilabu SA, De-Beer M, Peenze I, Steele AD. Diversity of human rotavirus VP6, VP7 and VP4 in Lagos State, Nigeria. J Health Popul Nutr. 2002;20:59-64.

5. Blutt SE, Miller AD, Salmon SL, Metzger DW, Conner ME. IgA is important for clearance and critical for protection from rotavirus infection. Mucosal Immunol. 2012;5:712-9.

6. Böhm R, Fleming FE, Maggioni A, Dang VT, Holloway G, Coulson BS, et al. Revisiting the role of histo-blood group antigens in rotavirus host-cell invasion. Nat Commun. 2015;6:5907.

7. Bonkoungou I, Sanou I, Bon F, Benon B, Coulibaly SO, Haukka $\mathrm{K}$, et al. Epidemiology of rotavirus infection among young children with acute diarrhoea in Burkina Faso. BMC Pediatr. 2010;10:94

8. Cardoso DDP, Soares CMA, Souza MBL, Azevado MSP, Martins RMB, Queiroz DAO, et al. Epidemiological features of rotavirus infection in Goiânia, Goiás, Brazil, from 1986 to 2000. Memor Inst Oswaldo Cruz. 2003;98:25-9.

9. Das S, Sahoo GC, Das P, Singh UK, Jaiswal AK, Singh P, et al. Evaluating the impact of breastfeeding on rotavirus antigenemia and disease severity in Indian children. PLoS ONE. 2016;11:e0146243.

10. Djeneba O, Damintoti K, Denise I, Marie Christella NW, Virgilio $\mathrm{P}$, Adrien B, et al. Prevalence of rotavirus, adenovirus and enteric parasites among pediatric patients attending Saint Camille Medical Centre Ouagadougou. Pak J Biol Sci. 2007;10:4266-70.

11. Elnady HG, Abdel Samie OM, Saleh MT, Sherif LS, Abdalmoneam N, Kholoussi NM, et al. ABO blood grouping in Egyptian children with rotavirus gastroenteritis. Przeglad Gastroenterol. 2017;12:175-80.

12. Esona MD, Armah GE, Steele AD. Molecular epidemiology of rotavirus infection in Western Cameroon. J Trop Paediatr. 2003;2003(49):160-3.

13. Gentsch JR, Hull JJ, Teel EN, Kerin TK, Freema MM, Esona $\mathrm{MD}$, et al. $\mathrm{G}$ and $\mathrm{P}$ Types of circulating rotavirus strains in the United States during 1996-2005: nine years of prevaccine data. J Infect Dis. 2009;2009(200):S99-109.

14. Gomwalk NE, Gosham LT, Umoh JU. Rotavirus gastroenteritis in paediatric diarrhoea in Jos, Nigeria. $\mathrm{J}$ Trop Paediatr. 1990;1990(36):52-5.

15. Hamza Y, Esengul K, Arzu G, Demirdoven M, Yazgan Z. Blood group and rotavirus gastroenteritis. Pediatr Infect Dis J. 2013;32:705-6.

16. Hu L, Crawford SE, Czako R, Cortes-Penfield NW, Smith DF, Le Pendu J, et al. Cell attachment protein VP8* of a human rotavirus specifically interacts with A-type histo-blood group antigen. Nature. 2012;485:256-9.

17. Karampatsas K, Osborne L, Seah ML, Tong CYW, Prendergast AJ. Clinical characteristics and complications of rotavirus gastroenteritis in children in east London: retrospective case-control study. PLoS ONE. 2018;13:e0194009.

18. Marie-Cardine A, Gourlain K, Mouterde O, Catignolles N, Marie-France H, Mallat E, et al. Epidemiology of acute viral gastroenteritis in children hospitalised in Rouen, France. Clin Infect Dis. 2002;34:1170-8.

19. Matson DO. On a multinational assessment of rotavirus disease in Europe. J Infect Dis. 2007;2007(195):S1-3.

20. Mwenda JM, Ntoto KM, Almaz A, Enweronu-Laryea C, Amina I, Mchomvu J, et al. Burden and epidemiology of rotavirus diarrhea in selected African countries: preliminary results from the African rotavirus surveillance network. J Infect Dis. 2010;202:S5-11.

21. Ndze NV, Akum AE, Kamga GH, Enjema LE, Esona MD, Banyai $\mathrm{K}$, et al. Epidemiology of rotavirus diarrhea in children under 5 years in Northern Cameroon. Pan Afr Med J. 2012;11:73.

22. Odimayo MS, Olanrewaju WI, Omilabu SA, Adegborod B. Prevalence of rotavirus-induced diarrhoea among children under 5 years in Ilorin, Nigeria. J Trop Paediatr. 2008;54:343-6.

23. Ogunsanya TI, Rotimi VO, Adenuga A. A study of the aetiological agents of childhood diarrhoea in Lagos, Nigeria. J Med Microbiol. 1994;40:10-4. 
24. Parashar UD, Bresee JS, Gentsch JR, Glass RI. Rotavirus. Emerg Infect Dis. 1998;4:561-70.

25. Pennap G, Peenze I, De Beer M, Pager CT, Kwaga JKP, Ogalla WN, et al. VP6 subgroup and VP7 serotype of human rotavirus in Zaria, Northern Nigeria. J Trop Paediatr. 2000;46:345-7.

26. Plenge-Bonig A, Soto-Ramirez N, Karmus W, Petersen G, Davis S, Forster J. Breastfeeding protects against acute gastroenteritis due to rotavirus in infants. Eur J Pediatr. 2010;169:1471-6.

27. Salinas B, Gonzalez G, Gonzalez R, Escaloma M, Materan M, Perez Schael I. Epidemiologic and clinical characteristics of rotavirus disease during five years of surveillance in Venezuela. Paediatr Infect Dis J. 2004;23:S161-7.

28. Solberg OD, Hasing ME, Trueba G, Eisenberg JN. Characterization of novel VP7, VP4, and VP6 genotypes of previously untypeable Group A rotavirus. Virology. 2009;385:58-67.

29. Steele AD, Nimzing L, Peenze I, de Beer MC, Geyer A, Angyo I, et al. Circulation of the novel G9 and G9 rotavirus strains in Nigeria in 1998/1999. J Med Virol. 2002;67:608-12.

30. Tagbo BN, Mwenda JM, Armah G, Obidike EO, Okafor UH, Oguonu $\mathrm{T}$, et al. Epidemiology of rotavirus diarrhea among children younger than 5 years in Enugu, South East Nigeria. Pediatr Infect Dis J. 2014;33:S19-22.
31. Tagbo BN, Chukwubuike C, Mwenda JM, Seheri MI, Armah G, Mphahele JM, et al. Molecular characterization of rotavirus strains circulating in Enugu Nigeria: 2011 to 2016. World J Vaccin. 2019;2019(9):22-36.

32. Tan M, Jiang X. Histo-blood group antigens: a common riche for Norovirus and Rotavirus. Expert Rev Mol Med. 2014;16:e5.

33. Tate JE, Burton AH, Boschi-Pinto C, Parashar UD, et al. Global, regional and national estimates of rotavirus mortality in children $<5$ years of age, 2000-2013. Clin Infect Dis. 2016;62:S96-105.

34. Van-Man N, Luan LT, Trach DD, Thanh NTH, Tu PV, Long NT, et al. Epidemiological profile and burden of rotavirus diarrhoea in Vietnam: 5 years of sentinel hospital surveillance, 1998-2003. J Infect Dis. 2005;2005(192):S127-32.

35. Wobudeya E, Bachou H, Karamagi CK, Kalyango JN, Mutebi E, Wamani H. Breastfeeding and the risk of rotavirus diarrhea in hospitalized infants in Uganda: a matched case control study. BMC Pediatr. 2011;11:17.

Publisher's Note Springer Nature remains neutral with regard to jurisdictional claims in published maps and institutional affiliations. 